\title{
Abordagem e Tratamento da Hiperglicemia Induzida por Glicocorticóides
}

\section{Management and Treatment of Glucocorticoid-Induced Hyperglycemia}

\author{
Sílvia PAREDES $\triangle^{1,2}$, Marta ALVES ${ }^{1}$ \\ Acta Med Port 2016 Sep;29(9):556-563 - http://dx.doi.org/10.20344/amp.7758
}

\section{RESUMO}

Introdução: Os glicocorticóides associam-se a vários efeitos adversos, entre os quais se destaca uma importante ação diabetogénica. A hiperglicemia induzida pelos glicocorticóides trata-se de uma condição com elevada prevalência e que condiciona importante morbimortalidade.

Material e Métodos: Realizou-se uma revisão da literatura relativa à abordagem e tratamento da hiperglicemia induzida pelos glicocorticóides

Resultados: Embora não totalmente esclarecidos, sabe-se que vários mecanismos concorrem de forma sinérgica, propiciando o aparecimento da hiperglicemia em doentes não diabéticos e o agravamento do controlo glicémico em diabéticos. A hiperglicemia induzida por glicocorticóides apresenta padrões característicos, mais marcada no momento pós-prandial e muito dependente do horário da toma do glicocorticóide. Apesar da existência de normas de orientação gerais para o tratamento da hiperglicemia em doentes em ambulatório e em doentes hospitalizados não críticos, o mesmo não acontece no que diz respeito ao tratamento da hiperglicemia induzida por glicocorticóides. E, de facto, frequentemente é difícil e exigente a abordagem deste tipo de hiperglicemia, sendo necessária uma atuação específica. Esta abordagem depende não só do glicocorticóide em causa, como também da sua dose, frequência e horário de administração. De igual forma, a escolha do esquema de tratamento também depende do tipo de terapêutica previamente usado. Discussão e Conclusão: Os autores fizeram uma revisão do tema, congregando e definindo linhas orientadoras para o tratamento da hiperglicemia induzida por glicocorticóides, em doentes diabéticos e não diabéticos, em regime de ambulatório ou internamento, que serão úteis em diferentes contextos e transversalmente às diversas especialidades.

Palavras-chave: Glucocorticóides/efeitos adversos; Hiperglicemia/diagnóstico; Hiperglicemia/induzida quimicamente; Hiperglicemia/ tratamento.

\section{ABSTRACT}

Introduction: Glucocorticoids have been associated to several side effects, specially a diabetogenic action, the most common and representative effect. Glucocorticoid-induced hyperglycemia is a common medical condition, with general associated morbidity and mortality.

Material and Methods: It was performed a literature review about the management and treatment of glucocorticoid-induced hyperglycemia.

Results: Through numerous not quite fully understood mechanics, glucocorticoids promote hyperglycemia in non-diabetic patients and worsen diabetes control in diabetic individuals. Glucocorticoid-induced hyperglycemia presents key patterns, enhanced in the postprandial period and scheduled-dependent. Despite the existence of guidelines for hyperglycemia treatment in non-critic hospitalized and non-hospitalized patients, there are no guidelines respecting glucocorticoid-induced hyperglycemia. Nevertheless, it is known that glucocorticoid-induced hyperglycemia is complex and demanding, requiring a specific approach. Indeed, glucocorticoid-induced hyperglycemia treatment depends on the glucocorticoid used, its dose, frequency and schedule. Furthermore, the scheme of treatment previously used by diabetic individuals also influences the choice of the new scheme.

Discussion and Conclusion: The authors reviewed the glucocorticoid induced-hyperglycemia thematic and propose strategies to approach and treat glucocorticoid induced-hyperglycemia in diabetic and non-diabetic individuals. This review is expected to be useful in different settings and crosswise to all medical specialties.

Keywords: Glucocorticoids/adverse effects; Hyperglycemia/chemically induced; Hyperglycemia/diagnosis; Hyperglycemia/therapy.

\section{INTRODUÇÃO}

Hiperglicemia induzida por glicocorticóides (HIG) é sinónimo de aumento anormal da glicose plasmática associada ao uso de glicocorticóides num doente com ou sem história prévia de diabetes. ${ }^{1}$

Múltiplos estudos demonstraram uma relação entre a hiperglicemia em doentes críticos hospitalizados e um prognóstico adverso..$^{2-4} \mathrm{O}$ mesmo se verificou em doentes hospitalizados não críticos, nos quais a hiperglicemia se associou a aumento da mortalidade, independentemente da presença de diabetes. ${ }^{5}$ De facto, foi sugerida uma as- sociação entre hiperglicemia e alterações no sistema imunitário, mediadores inflamatórios, cascata da coagulação e função endotelial. A hiperglicemia parece, igualmente, aumentar o risco de infeção ${ }^{5}$ e morbimortalidade, e ainda contribuir para o prolongamento do tempo de internamento e do custo associado. ${ }^{6,7}$

A prevalência da HIG varia de acordo com diferentes estudos. ${ }^{8}$ Estima-se que a sua incidência em doentes hospitalizados com ou sem história conhecida de diabetes varie entre $20 \%$ e $50 \% .{ }^{9}$ Esta condição é subdiagnosticada e

1. Serviço de Endocrinologia. Hospital de Braga. Braga. Portugal.

2. Departamento de Educação e Simulação Médica. Faculdade de Medicina. Universidade do Porto. Porto. Portugal.

$\triangle$ Autor correspondente: Sílvia Paredes. silvia.sparedes@gmail.com

Recebido: 18 de abril de 2016 - Aceite: 25 de julho de 2016 | Copyright @ Ordem dos Médicos 2016 
subtratada dada a ausência de um critério de diagnóstico bem definido e de linhas de orientação. ${ }^{5}$ Num estudo recente de âmbito intra-hospitalar verificou-se que a vigilância da glicemia capilar era realizada com frequência em doentes sob terapêutica com glicocorticóides, contudo a taxa de iniciação de terapêutica antidiabética perante o descontrolo glicémico era baixa. ${ }^{8}$ Mais, foi demonstrado que na maioria das vezes, os doentes com HIG são tratados com esquemas sliding scale. , $^{8,10}$ Contudo, sabe-se que estes esquemas não fornecem as necessidades basais de insulina, favorecem o aparecimento de episódios de hiperglicemia e hipoglicemia e não permitem um controlo glicémico eficaz. ${ }^{6}$

$\mathrm{Na}$ ausência de guidelines orientadoras de diagnóstico e tratamento da HIG, esta é abordada segundo os protocolos das instituições, quando existem, ou com base na experiência prática do clínico. Desta forma, os nossos objetivos são rever a fisiopatologia da HIG e congregar linhas orientadoras para a abordagem e tratamento desta condição.

\section{MATERIAL E MÉTODOS}

Realizámos uma revisão com base na pesquisa bibliográfica eletrónica nas bases de dados PubMed e SciELO. Usamos a query "glucocorticoid AND hyperglycemia" e incluímos todos os artigos publicados até 31 de janeiro de 2016, em língua portuguesa, inglesa ou espanhola. A partir dos artigos obtidos na pesquisa inicial, efetuamos a pesquisa manual das referências bibliográficas das publicações inicialmente obtidas. Excluímos os artigos duplicados, os artigos não adequados ao tema e os artigos sem texto integral disponível.

\section{RESULTADOS}

Fisiopatologia e especificidades da hiperglicemia induzidas pelos glicocorticóides

Os glicocorticóides são hormonas mediadoras finais do eixo hipotálamo-hipófise-suprarrenal e possuem um papel chave na regulação do sistema imune, na inflamação, na homeostasia cardiovascular e, mais importante, no metabolismo energético. ${ }^{11} \mathrm{Na}$ prática clínica são comumente usados pelos seus efeitos anti-inflamatórios, antialérgicos e imunossupressores, ${ }^{12}$ sendo vulgarmente usados nas exacerbações de doenças respiratórias, na doença inflamatória intestinal, nas doenças autoimunes e na terapêutica supressora pós-transplante. Diferem entre si pela sua potência e tempo de ação (Tabela 1). ${ }^{13,14}$

Estes fármacos possuem diversos efeitos laterais, entre os quais uma conhecida ação diabetogénica, ${ }^{12,15}$ que ocorre através de diferentes mecanismos: 1) aumentam a gliconeogénese hepática; 2) diminuem a captação periférica de glicose; 3) diminuem a sensibilidade à insulina e antagonizam o seu efeito; 4) inibem a secreção de insulina pelas células- $\beta$; e, 5) favorecem o aumento de ácidos gordos livres com a consequente lipotoxicidade a afetar negativamente a função da célula- $\beta .{ }^{11,12,16}$ Como resultado final, os glicocorticóides agravam o controlo metabólico de indivíduos diabéticos, sendo também responsáveis pela ocorrência de hiperglicemia em doentes não diabéticos. ${ }^{16}$

A HIG desenvolve-se precocemente após o início da terapêutica, ${ }^{17}$ geralmente em 1 a 2 dias e induz um padrão de hiperglicemia sobretudo pós-prandial. ${ }^{18} \mathrm{O}$ uso de glicocorticóides de ação intermédia pela manhã tende a provocar hiperglicemia durante os períodos pós-prandiais do almoço e do jantar. ${ }^{19}$ De facto, doentes tratados com prednisolona (glicocorticóide de ação intermédia mais utilizado na prática clínica) pela manhã apresentam elevação das glicemias capilares nos períodos entre as $12 \mathrm{~h}$ e as $24 \mathrm{~h} .{ }^{19}$ Ao mesmo tempo, estes doentes podem apresentar valores de glicose em jejum normais ou apenas ligeiramente elevados apesar da hiperglicemia ao longo do dia. Por sua vez, os glicocorticóides de ação intermédia usados duas ou mais vezes por dia causam hiperglicemia durante as 24 horas, mantendo-se a tendência para valores mais elevados predominantemente no período pós-prandial. Já os glicocorticóides de longa duração têm um efeito hiperglicemiante superior a 24 horas, de predomínio pós-prandial, com uma ligeira descida da glicemia durante o período noturno. ${ }^{20}$

Vários fatores de risco para o desenvolvimento de HIG estão descritos na literatura: ${ }^{14}$ dose e duração do tratamento glicocorticóide, idade do doente, índice de massa corporal, status de fumador, valor de hemoglobina glicosilada,

Tabela 1 - Doses equivalentes e duração de ação dos glicocorticóides mais usados na prática clinica13,14

\begin{tabular}{|c|c|c|c|}
\hline Composto (oral ou endovenoso) & Semivida biológica (horas) & Duração de ação & Dose equivalente (mg) \\
\hline Hidrocortisona & $8-12$ & Curta & 20 \\
\hline Cortisona & $8-12$ & Curta & 25 \\
\hline Prednisona & $12-16$ & Intermédia & 5 \\
\hline Prednisolona & $12-16$ & Intermédia & 5 \\
\hline Metilprednisolona & $12-16^{*}$ & Intermédia & 4 \\
\hline Deflazacorte & $12-16$ & Intermédia & 7,5 \\
\hline Triancinolona & $12-24$ & Intermédia & 4 \\
\hline Betametasona & $20-36^{*}$ & Longa & 0,75 \\
\hline Dexametasona & $20-36$ & Longa & 0,75 \\
\hline
\end{tabular}

* Semi-vida mais longa nas formulações depot 
taxa de filtração glomerular, raça, história familiar de diabetes e diminuição da sensibilidade à insulina previamente existente. ${ }^{14,16,21}$

\section{Abordagem}

A vigilância da glicemia capilar deve ser realizada em todos os doentes que iniciam terapêutica com glicocorticóides, seja em ambulatório ou em contexto hospitalar. Dado que a maioria dos casos de HIG se desenvolve precocemente após o início da corticoterapia, doentes não diabéticos que permaneçam com valores de glicemia dentro da normalidade, sem necessidade de terapêutica, e durante pelo menos, 48 horas, poderão dispensar a vigilância glicémica, ${ }^{17,22}$ exceto se o estado clínico ou a dose de glicocorticóide se modificarem.

Relativamente ao diagnóstico de diabetes, em doentes medicados com glicocorticóides, os critérios diagnósticos da American Diabetes Association (ADA) ${ }^{15}$ também se aplicam, contudo, dada a HIG ocorrer sobretudo no período pós-prandial, estes critérios não parecem possuir igual sensibilidade diagnóstica. A avaliação da glicose em jejum e da prova de tolerância à glicose oral, por serem executadas pela manhã em jejum, podem subestimar a disglicémia, sobretudo quando o doente se encontra sob terapêutica com glicocorticóides de duração intermédia pela manhã. Talvez a constatação de uma glicemia ocasional $\geq 200 \mathrm{mg} /$ $\mathrm{dL}$ num doente com sintomatologia sugestiva seja o mais sensível dos critérios de diagnóstico. Dado o padrão de insulinorresistência induzido pelos glicocorticóides, perante uma terapêutica com glicocorticóide de duração intermédia pela manhã, a avaliação da glicemia sensivelmente duas horas após o almoço ou antes do jantar parece ser o método mais sensível na deteção de valores nessa ordem. No entanto, não existem provas validadas para este método. Em suma, num doente que inicia este tipo de terapêutica (habitualmente de manhã), a vigilância da glicemia capilar é fundamental, sobretudo no que diz respeito à glicemia pós-prandial do almoço e pré e pós-prandial do jantar. ${ }^{14}$

Tal como ocorre com o diagnóstico, também não existem recomendações de sociedades científicas sobre quando iniciar terapêutica nem quais os valores alvo a atingir nos doentes sob terapêutica com glicocorticóides. Na ausência de guidelines dirigidas, parece-nos razoável seguir as orientações já estabelecidas no que diz respeito à diabetes. Regra geral, para a maioria dos indivíduos diabéticos, os objetivos de controlo glicémico são: glicemia pré-prandial < $130 \mathrm{mg} / \mathrm{dL}$, glicemia pós-prandial < $180 \mathrm{mg} / \mathrm{dL}$ e hemoglobina glicosilada $<7 \%{ }^{23}$

No que diz respeito a doentes hospitalizados, as linhas orientadoras regem-se por algumas particularidades. O diagnóstico de hiperglicemia, em doentes hospitalizados, tem sido definido como glicose plasmática $\geq 140 \mathrm{mg} /$ $\mathrm{dL},{ }^{18,23}$ independentemente da presença de diabetes. Nos doentes não críticos hospitalizados o valor alvo da glicemia pré-prandial deverá ser $<140 \mathrm{mg} / \mathrm{dL}$ enquanto o valor alvo de uma glicemia aleatória deverá ser $<180 \mathrm{mg} / \mathrm{dL}$. Estes valores alvo deverão ser atingidos de forma segura, ajustados conforme as comorbilidades do doente, tentando evitar-se a ocorrência de hipoglicemias. ${ }^{23}$ As recomendações da Endocrine Society para o tratamento da hiperglicemia em doentes não críticos hospitalizados referem valores alvo entre 100 e $180 \mathrm{mg} / \mathrm{dL}$, acrescentando ainda que quando os valores de glicemia são $<100 \mathrm{mg} / \mathrm{dL}$ a terapêutica antidiabética deve ser reajustada de forma a evitar hipoglicemias. ${ }^{24}$ Nas recentes recomendações conjuntas da Sociedade Portuguesa de Diabetologia e da Sociedade Portuguesa de Medicina Interna recomendam-se alvos de glicemia pré-prandial inferior a $140 \mathrm{mg} / \mathrm{dL}$ e ocasional inferior a $180 \mathrm{mg} / \mathrm{dL}$ (Recomendações Conjuntas da Sociedade Portuguesa de Diabetologia (SPD) /Sociedade Portuguesa de Medicina Interna (SPMI), não publicado). Sendo assim, em doentes internados parece razoável recomendar o início de tratamento para valores de glicemia pré-prandial $>140 \mathrm{mg} / \mathrm{dL}^{20}$ e para valores aleatórios persistentemente acima de $180 \mathrm{mg} / \mathrm{dL} .{ }^{18}$ Todavia, sabe-se que alguns autores recomendam o início de tratamento para valores pós-prandiais apenas $\geq 200 \mathrm{mg} / \mathrm{dL} .{ }^{14}$

Aos doentes diabéticos e aos doentes sem este diagnóstico mas com valores de glicemia capilar > $140 \mathrm{mg} / \mathrm{dL}$, deve igualmente pedir-se o doseamento da hemoglobina glicosilada, caso não esteja documentada nos últimos 2 - 3 meses. ${ }^{20}$ Uma hemoglobina glicosilada $\geq 6,5 \%$ é diagnóstica de diabetes e permite distinguir uma diabetes pré-existente da hiperglicemia induzida pela corticoterapia. Deve ter-se em atenção que qualquer transfusão recente pode causar uma falsa diminuição da hemoglobina glicosilada. ${ }^{18}$

\section{Tratamento da HIG}

A maioria dos autores aponta a insulina como o fármaco de eleição no tratamento da HIG. Contudo, outros autores referem que outros fármacos podem ser usados dependendo do padrão de hiperglicemia, do glicocorticóide usado e das características do doente. ${ }^{14,16,25}$

\section{Antidiabéticos orais e injetáveis não insulínicos}

Muitos autores apontam várias razões para preterir estes fármacos no tratamento da HIG: 1) a potência dos fármacos pode ser insuficiente dada a robusta insulinorresistência causada pelos glicocorticóides; 2) a farmacocinética e farmacodinâmica destes fármacos podem não ser adequadas (inicio de ação lento, dificuldade de titulação de dose) ao padrão de insulinorresistência dos glicocorticóides; 3) a ausência de cobertura adequada ao tipo de hiperglicemia causada pelos glicocorticóides (pós-prandial); 4) muitas das patologias que levam à necessidade de corticoterapia contraindicam o uso destes fármacos; e, 5) muitos destes doentes encontram-se numa situação pouco estável, em que o perfil farmacológico destes antidiabéticos pode não ser seguro.

Porém, alguns estudos mais recentes têm vindo a demonstrar eficácia da metformina, ${ }^{26}$ das tiazolidinedionas, ${ }^{27}$ dos inibidores da DPP $-4,,^{28,29}$ dos agonistas do GLP-1 ${ }^{30,31} \mathrm{e}$ dos inibidores da a-glicosidase, ${ }^{32}$ em contextos particulares, no tratamento da HIG. 
A metformina e as tiazolidinedionas, por terem uma ação insulinossensibilizadora, atuam num dos mecanismos hiperglicemiantes dos glicocorticóides e por essa razão podem ser ponderadas no tratamento da HIG. Contudo, o seu lento início de ação torna o seu uso muito limitado. ${ }^{25}$ Além disso, muitos dos doentes hospitalizados apresentam insuficiência renal ou alguma condição predisponente à acidose láctica ou ainda doença cardíaca, o que contraindica o uso da metformina e das tiazolidinedionas, respetivamente, neste contexto. As tiazolidinedionas e os glicocorticóides aumentam o risco de fraturas, pelo que o seu uso simultâneo prolongado não deverá ser privilegiado. ${ }^{17}$

Quando se usam glicocorticóides de curta duração administrados pela manhã, não se aconselha o uso concomitante de sulfonilureias, dado o risco de hipoglicemia noturna. A administração de um glicocorticóide duas vezes por dia ou a administração de um glicocorticóide de longa duração induz um padrão de insulinorresistência durante 24 horas, pelo que, nestes casos, as sulfonilureias podem ser uma opção terapêutica. ${ }^{17}$ Contudo, aumentam o risco de hipoglicemia após uma retirada da dose noturna de glicocorticóide. ${ }^{25}$ As sulfonilureias comportam ainda o risco de hipoglicemia em doentes que de forma não previsível deixam de comer. ${ }^{18}$

Os inibidores da DPP-4 aumentam a secreção de insulina e diminuem a secreção de glucagon, condicionando um importante efeito anti-hiperglicemiante na glicemia pós-prandial. Apresentam ainda um rápido início de ação e um baixo risco de hipoglicemia uma vez que atuam de forma glicose-dependente. Desta forma, parecem poder ser usados de forma segura em doentes tratados com glicocorticóides de curta duração em dose única pela manhã, ${ }^{17,33}$ embora a experiência com estes fármacos, neste contexto, seja ainda muito limitada.

As glinidas têm um início de ação imediato e uma curta duração de ação, adaptando-se ao perfil de hiperglicemia pós-prandial induzida pelos glicocorticóides, não havendo contudo estudos a validar o seu uso neste contexto.

Em geral, os fármacos antidiabéticos orais e injetáveis além da insulina poderão ser uma opção em doentes sem diabetes ou com diabetes bem controlada previamente com estes fármacos, sob terapêutica com baixas doses de glicocorticóides e glicemias capilares elevadas, mas sustentadamente inferiores a $200 \mathrm{mg} / \mathrm{dL} .{ }^{14,17}$

\section{Insulina}

A insulina é o tratamento de eleição em doentes com glicemias persistentemente acima de $200 \mathrm{mg} / \mathrm{dL}$ e em doentes internados. ${ }^{17} \mathrm{~A}$ insulina apresenta um rápido início de ação e pode ser facilmente titulada. ${ }^{14} \mathrm{O}$ tipo de insulina $\mathrm{e}$ o esquema a usar dependem da presença ou ausência de insulinoterapia prévia, do esquema habitualmente usado e ainda, do tipo de glicocorticóide e do horário de administração. A dose de insulina inicial vai depender do peso do doente bem como do tipo e dose de glicocorticóide a usar (Tabela 2). ${ }^{14}$

Início de insulinoterapia em doentes sem insulinoterapia prévia ${ }^{7,14,17,20,25}$

Terapêutica com glicocorticóide de duração intermédia, uma administração pela manhã. Deve iniciar-se insulina NPH antes do pequeno-almoço, pois o seu perfil de ação acompanha o efeito hiperglicemiante do glicocorticóide. Desta forma, evitar-se-ão as hiperglicemias pela tarde e antes do jantar e, pela sua duração de ação, não haverá risco de hipoglicemias antes do pequeno-almoço. A terapêutica oral prévia pode ser mantida caso não haja contraindicação para o seu uso.

Terapêutica com glicocorticóide de duração intermédia, $\geq$ duas administrações por dia. Deve iniciar-se insulina NPH distribuindo-se a dose estimada da seguinte forma: 2/3 antes do pequeno-almoço e 1/3 antes do jantar. Alterações na dose de glicocorticóide pela manhã devem acompanhar-se de ajuste da dose de insulina antes do pequeno-almoço, tal como alterações na dose de glicocorticóide à noite requerem um ajuste da dose de insulina antes do jantar.

Terapêutica com glicocorticóide de longa duração ou intra-articular. Deve iniciar-se insulina glargina numa única administração ou insulina detemir em duas administrações. A duração de ação destas insulinas acompanha a duração de ação do glicocorticóide permitindo uma correção da hiperglicemia ao longo do dia. Relativamente à administração intra-articular, deve ter-se o cuidado de suspender a administração de insulina dois a três dias após a última infiltração.

\section{Ajuste de insulinoterapia em doente com esquema pré- vio de insulina $7,14,17,20,25$}

Nestes casos, deve-se calcular a dose de insulina adicional necessária de acordo com a Tabela 2. O esquema de insulina deverá ser mantido e a este deverão ser acrescentadas as doses de insulina calculadas.

Terapêutica com glicocorticóide de duração intermédia, uma administração pela manhã. Se o doente faz habitualmente insulina NPH à noite ou insulina glargina ou

Tabela 2 - Estimativa da dose inicial de insulina de acordo com o peso do doente e o tipo e dose de glicocorticóide ${ }^{14}$

\begin{tabular}{llll}
\hline Prednisolona (mg/dia) & Insulina NPH (Ul/kg/dia) & Dexametasona (mg/dia) & Insulina glargina / detemir (Ul/kg/dia) \\
\hline 10 & 0,1 & 2 & 0,1 \\
20 & 0,2 & 4 & 0,2 \\
30 & 0,3 & 6 & 0,3 \\
$\geq 40$ & 0,4 & $\geq 8$ & 0,4 \\
\hline
\end{tabular}


determir, deve adicionar-se a dose de insulina NPH calculada antes do pequeno-almoço. Se o doente faz habitualmente insulina NPH em duas administrações diárias, deve adicionar-se a dose de insulina NPH calculada à dose da manhã. Se o doente faz habitualmente um esquema basal-bólus, deve manter-se a dose de insulina basal prévia e adicionar-se o equivalente à dose de insulina NPH estima- da em bólus, nomeadamente $20 \%$ antes do pequeno-almoço, $40 \%$ antes do almoço e $40 \%$ antes do jantar.

Terapêutica com glicocorticóide de duração intermédia, $\geq$ duas administrações por dia. Se o doente faz habitualmente insulina NPH à noite ou duas vezes por dia, deve adicionar-se a dose de insulina NPH estimada, distribuindo a mesma por $2 / 3$ antes do pequeno-almoço e

Tabela 3 - Abordagem terapêutica da hiperglicemia induzida por glicocorticóides em doentes previamente insulinotratados, de acordo com o esquema de insulinoterapia prévio, o tipo e horário de toma do glicocorticóide $14,17,20,25$

\begin{tabular}{ll}
\hline Terapêutica com glicocorticóide de duração intermédia, 1 administração pela manhã \\
\hline Esquema prévio & Recomendação \\
\hline Insulina NPH ao jantar ou deitar & Adicionar a dose de insulina NPH calculada antes do pequeno-almoço \\
Insulina NPH duas vezes por dia & $\begin{array}{l}\text { Adicionar a dose de insulina NPH calculada à dose que já administrava antes do pequeno- } \\
\text { almoço }\end{array}$ \\
Insulina glargina ou determir & Adicionar a dose de insulina NPH calculada antes do pequeno-almoço \\
Esquema basal-bólus & $\begin{array}{l}\text { Adicionar o equivalente à dose de insulina NPH estimada, em bólus, distribuídos da seguinte } \\
\text { forma: }\end{array}$ \\
& $-20 \%$ antes do pequeno-almoço \\
& $-40 \%$ antes do almoço
\end{tabular}

Terapêutica com glicocorticóide de duração intermédia, $\geq 2$ administrações por dia

Esquema prévio Recomendação

Insulina NPH ao jantar ou deitar Adicionar a dose de insulina NPH estimada, distribuída da seguinte forma:

- 2/3 antes do pequeno-almoço

- $1 / 3$ antes do jantar

Insulina NPH duas vezes por dia Adicionar a dose de insulina NPH estimada, distribuída da seguinte forma:

- 2/3 antes do pequeno-almoço

- $1 / 3$ antes do jantar

Insulina glargina ou detemir

Adicionar a dose de insulina calculada, distribuída da seguinte forma:

- 2/3 sob a forma de insulina NPH administrada antes do pequeno-almoço

-1/3 adicionar à dose de insulina glargina ou determir habitual, a administrar antes do jantar.

Esquema basal-bólus

Adicionar a insulina estimada, distribuída da seguinte forma:

- $25 \%$ sob a forma de insulina basal

- $75 \%$ sob a forma de bólus, distribuindo do seguinte modo:

- 1/3 antes do pequeno-almoço

- 1/3 antes do almoço

- $1 / 3$ antes do jantar

Terapêutica com glicocorticóide de longa duração ou intra-articular

\begin{tabular}{|c|c|}
\hline Esquema prévio & Recomendação \\
\hline Insulina NPH ao jantar ou deitar & $\begin{array}{l}\text { Adicionar a dose de insulina NPH estimada, distribuída da se } \\
\text { - } 2 / 3 \text { antes do pequeno-almoço } \\
\text { - } 1 / 3 \text { antes do jantar }\end{array}$ \\
\hline Insulina NPH duas vezes por dia & $\begin{array}{l}\text { Adicionar a dose de insulina NPH estimada, distribuída da se } \\
\cdot 2 / 3 \text { antes do pequeno-almoço } \\
\cdot 1 / 3 \text { antes do jantar }\end{array}$ \\
\hline Insulina glargina ou detemir & Adicionar a dose de insulina estimada ao esquema habitual \\
\hline Esquema basal-bólus & $\begin{array}{l}\text { Adicionar a insulina estimada, distribuída da seguinte forma: } \\
\text { - } 25 \% \text { sob a forma de insulina basal } \\
\cdot 75 \% \text { sob a forma de bólus, distribuindo do seguinte modo: } \\
\text { - } 1 / 3 \text { antes do pequeno-almoço } \\
\cdot 1 / 3 \text { antes do almoço } \\
\text { - } 1 / 3 \text { antes do jantar }\end{array}$ \\
\hline
\end{tabular}


$1 / 3$ antes do jantar. Se o doente faz habitualmente insulina glargina ou detemir, deve-se calcular a dose adicional de insulina necessária e distribuir-se da seguinte forma: 2/3 devem ser dados sob a forma de insulina NPH antes do pequeno-almoço; o restante $1 / 3$ deverá ser adicionado à dose de insulina glargina ou determir habitual, a administrar antes do jantar. Se o doente faz habitualmente um esquema de insulina basal-bólus, deve adicionar-se a insulina estimada em $25 \%$ sob a forma de insulina basal e em $75 \%$ sob a forma de bólus, distribuídos de forma igual pelas três principais refeições.

Terapêutica com glicocorticóide de longa duração ou intra-articular. Se o doente faz habitualmente insulina $\mathrm{NPH}$ uma ou duas vezes por dia, deve adicionar-se a dose de insulina NPH estimada, distribuindo-se 2/3 para a dose a administrar antes do pequeno-almoço e 1/3 para a dose a administrar antes do jantar. Se o doente faz habitualmente insulina glargina ou detemir, deve adicionar-se a dose de insulina basal estimada ao esquema habitual. Se o doente faz habitualmente um esquema de insulina basal-bólus, deve adicionar-se a dose de insulina estimada, $25 \%$ sob a forma de insulina basal e $75 \%$ sob a forma de bólus, distribuídos de forma igual pelas três principais refeições.

A Tabela 3 sumariza estas recomendações.

\section{Ajustes de insulinoterapia}

Os ajustes de insulina devem ser realizados diariamente (Recomendações Conjuntas da Sociedade Portuguesa de Diabetologia (SPD) /Sociedade Portuguesa de Medicina Interna (SPMI), não publicadas) ou no máximo a cada dois a três dias, ${ }^{17}$ de acordo com o valor das glicemias capilares e com incrementos ou diminuições de cerca de $20 \%$, para doses estáveis de glicocorticóide.

Doses adicionais de insulina de correção rápida devem ser usadas, se necessário, de forma a atingir os valores alvo de glicemia capilar. ${ }^{22}$

Alterações nas doses de insulina devem igualmente ocorrer sempre que se prevê ou se altera a dose do glicocorticóide, de forma a evitar hiper ou hipoglicemias. Regra geral, a percentagem de insulina a alterar deve corresponder a $50 \%$ da percentagem de alteração do glicocorticóide. ${ }^{17}$ Por exemplo, num doente medicado com prednisolona 60mg pela manhã e 28 unidades de insulina NPH pela manhã, caso se pretenda a redução do glicocorticóide para $30 \mathrm{mg} /$ dia, o que corresponde a uma redução de $50 \%$, dever-se-á reduzir a insulina em $25 \%$, o correspondente, neste caso, a sete unidades. Desta forma, o doente passaria a administrar 21 unidades de NPH pela manhã.

De seguida, exemplificam-se alguns esquemas concretos de ajuste de insulina em resposta à modificação da dose do glicocorticóide: 20

Redução da terapêutica com glicocorticóide de duração intermédia, 1 administração pela manhã. Dever-se-á diminuir a dose de NPH da manhã em $20 \%$ - 30\% ou então de forma proporcional à redução do glicocorticóide, como supracitado. Em doentes com esquema basal-bólus dever-se-á reduzir aos bólus pré-prandiais, nomeadamente
$20 \%$ ao pequeno-almoço, 30\% ao almoço e $30 \%$ ao jantar.

Redução da terapêutica com glicocorticóide de duração intermédia, $\geq$ duas administrações por dia. Dever-se-á diminuir todas as doses de insulina em $20-30 \%$ ou então de forma proporcional à redução do glicocorticóide, como supracitado. Em diabéticos, quando se altera um esquema com mais de uma administração por dia para apenas uma administração pela manhã, dever-se-á diminuir a dose da insulina basal da noite em $50 \%$. Em doentes com HIG, quando se altera um esquema com mais de uma administração por dia para apenas uma administração pela manhã, a toma noturna de insulina deve ser suspensa. ${ }^{20}$

\section{Suspensão da corticoterapia}

Após suspensão do glicocorticóide, o diabético com bom controlo glicémico prévio pode retomar o esquema de tratamento habitual. Em doentes com diabetes desencadeada pelos glicocorticóides a insulinoterapia deve ser suspensa. Em diabéticos com mau controlo glicémico prévio deve ser feito um ajuste terapêutico. ${ }^{20}$

\section{Terapêutica prolongada com glicocorticóides em baixa dose}

Alguns doentes apresentam patologias que requerem corticoterapia crónica, como por exemplo, doentes com patologia reumatológica, com doenças autoimunes ou transplantados. Estes doentes poderão apresentar necessidade de manter a corticoterapia por tempo prolongado ou até indeterminado, sendo que o tipo de glicocorticóide, a dose e a frequência muito diferem da corticoterapia usada em contexto agudo. Desta forma, a abordagem e terapêutica usada nestas situações deverá ser adaptada a este esquema de tratamento que possui algumas particularidades. De facto, a utilização de um glicocorticóide de ação intermédia, geralmente pela manhã, em doses baixas e estáveis é a forma mais frequente de administração. Este tipo de terapêutica causa um padrão de hiperglicemia diferente do descrito inicialmente, caracterizado por maior estabilidade e menor severidade, o que justifica uma abordagem e tratamento distintos. Neste caso, o início de ação rápido e a possibilidade de titulação tornam-se critérios menos relevantes, e a escolha do fármaco anti-hiperglicemiante deve ser feita tendo em conta o seu perfil de ação e os mecanismos hiperglicemiantes dos glicocorticóides. Em termos farmacológicos, a metformina, pela sua ação insulinossensibilizadora, parece ser o fármaco de primeira linha. Em caso de intolerância ou contraindicação, a pioglitazona, pelo similar mecanismo de ação, é um fármaco de escoIha. Os fármacos de segunda linha são as sulfonilureias, as glinidas, os inibidores da DPP-4, os agonistas do GLP-1 e a insulina, todos podendo ser usados dependendo do seu perfil de ação, tolerância e risco de hipoglicemia, sobretudo noturno. Muitas vezes, associam-se à corticoterapia outros imunossupressores, como o tacrolimus e a ciclosporina, que possuem efeitos deletérios no metabolismo dos hidratos de carbono. Nestes casos, a hiperglicemia é resultante dos efeitos combinados dos dois grupos farmacológicos e o 
tratamento com insulina é muitas vezes necessário. Quando se inicia um esquema terapêutico com insulina, geralmente opta-se pelo uso de uma insulina intermédia antes do pequeno-almoço. Neste caso, os fármacos nsulinossensibilizadores deverão ser mantidos, enquanto os restantes fármacos hipoglicemiantes devem ser suspensos. ${ }^{14,25,34}$

\section{DISCUSSÃO E CONCLUSÃO}

A HIG é uma condição muito prevalente, subvalorizada, subdiagnosticada e subtratada e que merece a atenção transversal das diferentes especialidades médicas pela importante morbimortalidade a que se associa. Trata-se de um problema real em doentes diabéticos e não diabéticos, em ambulatório ou em regime de internamento e que requer um diagnóstico precoce, uma correta abordagem e um tratamento eficaz.

A vigilância da glicemia capilar em doentes que iniciam tratamento com glicocorticóide é indispensável, mesmo na ausência de diabetes. O tratamento deve ser iniciado em doentes que apresentem hiperglicemia e deve privilegiar-se uma estratégia que simultaneamente minimize as hipoglicemias e permita atingir o controlo glicémico adequado. Na maioria dos casos, a insulina é o fármaco de primeira linha. Contudo, e em determinadas condições, outros fármacos além da insulina poderão ser usados. Os esquemas de insulina dependem do doente em causa, do tipo e horário de administração do glicocorticóide e do tratamento prévio no doente diabético. $\mathrm{O}$ ajuste de insulina deve realizar-se

\section{REFERÊNCIAS}

1. Hwang JL, Weiss RE. Steroid-induced diabetes: a clinical and molecular approach to understanding and treatment. Diabetes Metab Res Rev. 2014;30:96-102.

2. Capes SE, Hunt D, Malmberg K, Gerstein HC. Stress hyperglycaemia and increased risk of death after myocardial infarction in patients with and without diabetes: a systematic overview. Lancet. 2000;355:773-8.

3. Finney SJ, Zekveld C, Elia A, Evans TW. Glucose control and mortality in critically ill patients. JAMA. 2003;290:2041-7.

4. Cheung NW, Li S, Ma G, Crampton R. The relationship between admission blood glucose levels and hospital mortality. Diabetologia. 2008;51:952-5.

5. Papak J, Kansagara D. Management of hyperglycemia in a hospitalized patient with diabetes mellitus and cardiovascular disease. Am J Cardiol. 2012;110:24B-31

6. Botella M, Rubio JA, Percovich JC, Platero E, Tasende C, Álvarez J. Glycemic control in non-critical hospitalized patients. Endocrinol Nutr. 2011;58:536-40.

7. Tamez-Pérez HE, Quintanilla-Flores DL, Proskauer-Peña SL, GonzálezGonzález JG, Hernández-Coria MI, Garza-Garza LA, et al. Inpatient hyperglycemia: Clinical management needs in teaching hospital. J Clin Transl Endocrinol. 2014;1:176-8.

8. Fong $\mathrm{AC}$, Cheung NW. The high incidence of steroid-induced hyperglycaemia in hospital. Diabetes Res Clin Pract. 2013;99:277-80.

9. Houlden R, Capes S, Clement M, Miller D. In-hospital management of diabetes. Can J Diabetes. 2013;37:S77-81.

10. Gerards MC, Tervaert EC, Hoekstra JB, Vriesendorp TM, Gerdes VE. Physician's attitudes towards diagnosing and treating glucocorticoid induced hyperglycaemia: Sliding scale regimen is still widely used despite guidelines. Diabetes Res Clin Pract. 2015;109:246-52.

11. Paredes S, Ribeiro L. Cortisol: the villain in metabolic syndrome? Rev Assoc Med Bras. 2014;60:84-92.

12. Rafacho A, Ortsater H, Nadal A, Quesada I. Glucocorticoid treatment and endocrine pancreas function: implications for glucose homeostasis, insulin resistance and diabetes. J Endocrinol. 2014;223:R49-62.

13. Bruton LL, Lazo JS, Parker KL. As bases farmacológicas da terapêutica sempre que há uma alteração na dose do glicocorticóide.

Apesar da sua prevalência, muito permanece por saber no que diz respeito à HIG. Uma melhor compreensão dos mecanismos fisiopatológicos envolvidos na HIG permitirá, certamente, um tratamento mais eficaz. Estudos clínicos são necessários para avaliar o real impacto da HIG e do seu tratamento na morbimortalidade dos doentes que temporária ou permanentemente desta terapêutica precisam.

\section{PROTECÇÃO DE PESSOAS E ANIMAIS}

Os autores declaram que os procedimentos seguidos estavam de acordo com os regulamentos estabelecidos pelos responsáveis da Comissão de Investigação Clínica e Ética e de acordo com a Declaração de Helsínquia da Associação Médica Mundial.

\section{CONFIDENCIALIDADE DOS DADOS}

Os autores declaram ter seguido os protocolos do seu centro de trabalho acerca da publicação de dados.

\section{CONFLITOS DE INTERESSE}

Os autores declaram não terem qualquer conflito de interesse relativamente ao presente artigo.

\section{FONTES DE FINANCIAMENTO}

Os autores declaram não ter recebido subsídios ou bolsas para a elaboração do artigo.

de Goodman \& Gilman. 10ª ed. Rio de Janeiro: McGraw Hill; 2005.

14. Perez A, Jansen-Chaparro S, Saigi I, Bernal-Lopez MR, Minambres I, Gomez-Huelgas R. Glucocorticoid-induced hyperglycemia. J Diabetes. 2014;6:9-20.

15. American Diabetes Association. Diagnosis and classification of diabetes mellitus. Diabetes Care. 2012;35:S64-71.

16. Katsuyama T, Sada KE, Namba S, Watanabe H, Katsuyama E, Yamanari T, et al. Risk factors for the development of glucocorticoidinduced diabetes mellitus. Diabetes Res Clin Pract. 2015;108:273-9.

17. Tamez-Perez HE, Quintanilla-Flores DL, Rodriguez-Gutierrez R, Gonzalez-Gonzalez JG, Tamez-Pena AL. Steroid hyperglycemia: prevalence, early detection and therapeutic recommendations. A narrative review. World J Diabetes. 2015;6:1073-81.

18. Magaji V, Johnston JM. Inpatient management of hyperglycemia and diabetes. Clin Diabetes. 2011;29:3-9.

19. Burt MG, Roberts GW, Aguilar-Loza NR, Frith P, Stranks SN. Continuous monitoring of circadian glycemic patterns in patients receiving prednisolone for COPD. J Clin Endocrinol Metab. 2011;96:1789-96.

20. Saigi I, Perez A. Manejo de la hiperglucemia inducida por corticoides. Rev Clin Esp. 2010;210:397-403.

21. Sugiyama T, Sugimoto T, Suzuki S, Sato Y, Tanaka T, Tatsuno I. Current smoking is an independent risk factor for new-onset diabetes mellitus during highdose glucocorticoid treatment. Int $\mathrm{J}$ Clin Pharmacol Ther. 2015;53:616-20.

22. Baldwin D, Apel J. Management of hyperglycemia in hospitalized patients with renal insufficiency or steroid-induced diabetes. Curr Diab Rep. 2013;13:114-20.

23. American Diabetes Association. Standards of medical care in diabetes 2016. Diabetes Care. 2016;39:S1-112.

24. Murad MH, Coburn JA, Coto-Yglesias F, Dzyubak S, Hazem A, Lane MA, et al. Glycemic control in non-critically ill hospitalized patients: a systematic review and meta-analysis. J Clin Endocrinol Metab. 2012;97:49-58.

25. Ullastre I Pérez A. Hiperglucemia inducida por glucocorticoides. Semin Fund Esp Reumatol. 2011;12:1-8. 
26. Bostrom B, Uppal P, Chu J, Messinger Y, Gandrud L, McEvoy R. Safety and efficacy of metformin for therapy-induced hyperglycemia in children with acute lymphoblastic leukemia. J Pediatr Hematol Oncol. 2013;35:504-8.

27. Willi SM, Kennedy A, Brant BP, Wallace P, Rogers NL, Garvey WT. Effective use of thiazolidinediones for the treatment of glucocorticoidinduced diabetes. Diabetes Res Clin Pract. 2002;58:87-96.

28. Yanai H, Masui Y, Yoshikawa R, Kunimatsu J, Kaneko H. Dipeptidyl peptidase-4 inhibitor for steroid-induced diabetes. World J Diabetes. 2010;1:99-100.

29. Katsuyama $H$, Sako A, Adachi $H$, Hamasaki $H$, Yanai $H$. Effects of 6-month sitagliptin treatment on metabolic parameters in diabetic patients taking oral glucocorticoids: a retrospective cohort study. J Clin Med Res. 2015;7:479-84.

30. van Raalte DH, van Genugten RE, Linssen MM, Ouwens DM, Diamant
M. Glucagon-like peptide-1 receptor agonist treatment prevents glucocorticoid-induced glucose intolerance and islet-cell dysfunction in humans. Diabetes Care. 2011;34:412-7.

31. Matsuo K, Nambu T, Matsuda Y, Kanai Y, Yonemitsu S, Muro S, et al. Evaluation of the effects of exenatide administration in patients with type 2 diabetes with worsened glycemic control caused by glucocorticoid therapy. Intern Med. 2013;52:89-95.

32. Dabhi AS, Bhatt NR, Shah MJ. Voglibose: an alpha glucosidase inhibitor. J Clin Diagn Res. 2013;7:3023-7.

33. Drucker DJ, Nauck MA. The incretin system: glucagon-like peptide-1 receptor agonists and dipeptidyl peptidase-4 inhibitors in type 2 diabetes. Lancet. 2006;368:1696-705.

34. John R, Fogelfeld L. Inpatient management of diabetes and hyperglycemia. Dis Mon. 2004;50:438-79. 